\title{
An investigation of rainfall variability in the upper and lower river Niger basin development authority areas, Nigeria
}

\author{
Babatolu J.S*, Akinnubi R.T., Akintade T.F, Omosuyi O.B \\ Adeyemi College of Education, Ondo \\ Department of Geography \\ Department of Physics \\ Department of Agricultural Science \\ *Corresponding author E-mail: rufus782000@yahoo.com
}

\begin{abstract}
The paper investigates annual rainfall variability in the Upper and Lower Niger Basin Development Authority Areas. The annual rainfall series is investigated for variability using Standardized Anomaly Index and Gaussian Lower pass filter. It is also examined for trends using Spearman's rank correlation coefficient. The annual rainfall over the study area exhibits multi-decadal drying trend from 1970-1993, as well as strong inter-annual variability. The annual rainfall series shows an insignificant trend during the 1941-2010 period but increasing trend during the 1980-2010 sub period. Recovery of annual rainfall occurred at the end of the long persistent dry period.
\end{abstract}

Keywords: Rainfall, anomalies, river Niger basin development authority area.

\section{Introduction}

There is strong scientific consensus that the earth's climate has changed and will continue to change as human activities increase the load of greenhouse gases in the atmosphere. Global warming over the past century has already had measurable effects. It contributes to melting of snow and ice, increase in rainfall, and increase in extreme weather conditions and rising global mean sea level [1-5]. The effect of global warming on rainfall is based on the premise that the warming earth will lead to intensifications of the hydrological cycle. This means warmer temperature will increase evaporation and a warmer atmosphere will be able to hold more moisture aloft, leading to increased precipitation will increase. It will not only increase precipitation amount but will also lead to changes in rainfall patterns and its spacetime distribution.

The Upper and Lower Niger River Basin Development Authority Area (U\&LNRBDA) located in the middle belt of Nigeria and Sudan-Guinean zone of West Africa like other parts of Africa has a long history of rainfall fluctuation of varying lengths and intensities. Droughts were observed to have occurred in 1940s and a long one from about 19691990[6-10]. In general there has been a decline in rainfall on the African continent since 1960s [11]. The most significant climate that has occurred in Africa is a long-term reduction in rainfall particularly in Semi-arid areas of Afric[12-14]. In West Africa a decline in annual rainfall has been observed since the end of the 1960s with decrease of 20-40\% recorded between the periods 1931-60 and 1968-1990 [15], [17]. Declines in mean annual rainfall in the tropical rain forest area of around 4\% in West Africa, 3\% in North Congo and 2\% on South Congo for the period 19601998[18]. East Africa is not left out. The region has been experiencing dramatic rainfall pattern with increasing rainfall in the northern sector and declining rainfall in the southern sector[19-21] Many current literatures on rainfall climate have indicated a wetter condition in the Sahel at the beginning of the 21st century, little is known about the SudanoGuinean zone of West Africa within which the study area lies. For instance, New [22] observed some amelioration of dry conditions in the Sahel in the 1990s and the positive trend in annual rainfall totals continued into the early years of the 21 st century. Brooks [23] also found that there has been some improvement in the Sahel's climate since 1990s and in 2003 there was abundant rainfall throughout much of the Sahel and also parts of the Sahara, prompting speculation that the region was experiencing a shift to a wetter climate.

Looking toward the future, the current projections on rainfall in Africa are less consistent than they are with respect to temperature. Nonetheless, the results of rainfall projections for the 21 st century by Intergovernmental Panel on Climate Change (IPCC) [2], North Africa, Southern Africa, East Africa including the Horn of Africa and the Mediterranean coastline are some of the regions where there is less uncertainty. However climate projections for West Africa show no 
clear outcome. Synthesizing the climate change projections for West Africa, slight wetter condition in the Sahelian region with no real changes along the Sudano-Guinea and Guinean coast can be inferred. There remains, therefore, many uncertainties vis-à-vis the future climate of these zones. IPCC [2] concludes that precipitation has increased in the Sahel region and other parts of the tropical Africa since 1979.

Rainfall changes are very important to consider when assessing climate change effects. It is therefore, necessary to constantly monitor rainfall trends. Since these studies were carried out a number of major climate anomalies might have taken place. The present study, therefore, aims in part at updating these studies and is focused specifically on the U\&LNRBDA area. Furthermore, whether or not rainfall will increase or decrease remains difficult to project for specific regions. The uncertainty in the West African future climate trends and impact make it imperative to embark on detailed analysis of her climate particularly Sudano-Guinean zone, an area often neglected in earlier studies. Again the current spate of flooding in the country calls for detail information about the space and time distribution of rainfall amount change and what the change entails.

This study, therefore, documents the rainfall variability that has occurred in U\&LNRBDA during 1941-2010 periods.

\section{Material and method}

\subsection{The study area}

The study area which covers the Upper and Lower Niger River Basin Development Authorities area (U\&LNRBDA) is located mainly between latitudes 70 and $120 \mathrm{~N}$ and between longitude 30 and $90 \mathrm{E}$ in Nigeria. (Figs.1\&2).

The southern and western borders of the area are occupied by the Western Upland rising above 600 metres while the north and north east are occupied by North-Central Plateau reaching about 1200 metres at its highest part. These highlands are separated by the Niger trough which is believed to be at one time an arm of the Atlantic Ocean in which older sedimentary rocks were deposited. The trough mainly consists of the Niger flood plain.

The U\&LNRBDA area lies within the middle belt of Nigeria, a region of vulnerability with high seasonal and interannual rainfall variability. The study area enjoys distinct wet and dry seasons. The wet and dry seasons are associated respectively with the prevalence of the moist maritime south-westerly monsoon from the Atlantic Ocean and the dry continental north-easterly wind from the Sahara desert. The annual rainfall varies between $1040 \mathrm{~mm}$ and $1260 \mathrm{~mm}$ over the region. The mean annual temperature is $27.40 \mathrm{C}$.

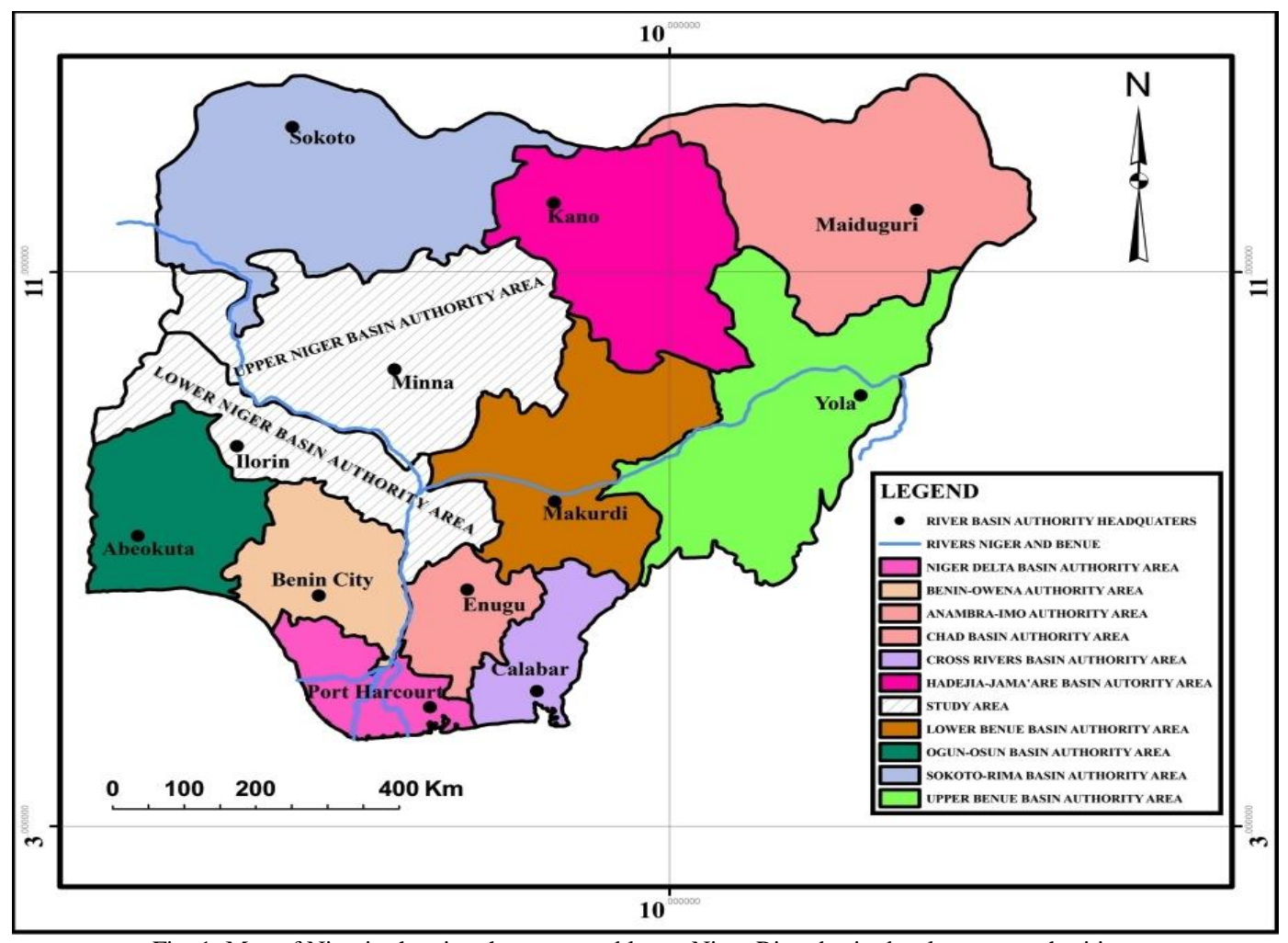

Fig. 1: Map of Nigeria showing the upper and lower Niger River basin development authorities. 
The area is drained by many rivers including Niger, Kaduna, Kotangora, Swashi, Kampe, Galma amongst others.The area is vegetated by forest savanna mosaic found on small pocket of land in the southern part where climate permits the growth of forest. Guinea savanna forms the main vegetation of the area except the Niger flood plain. The vegetation decreases in luxuriance northward in sympathy with rainfall amounts.

A large percentage of the inhabitants are peasant farmers and rain-fed agriculture is very important.

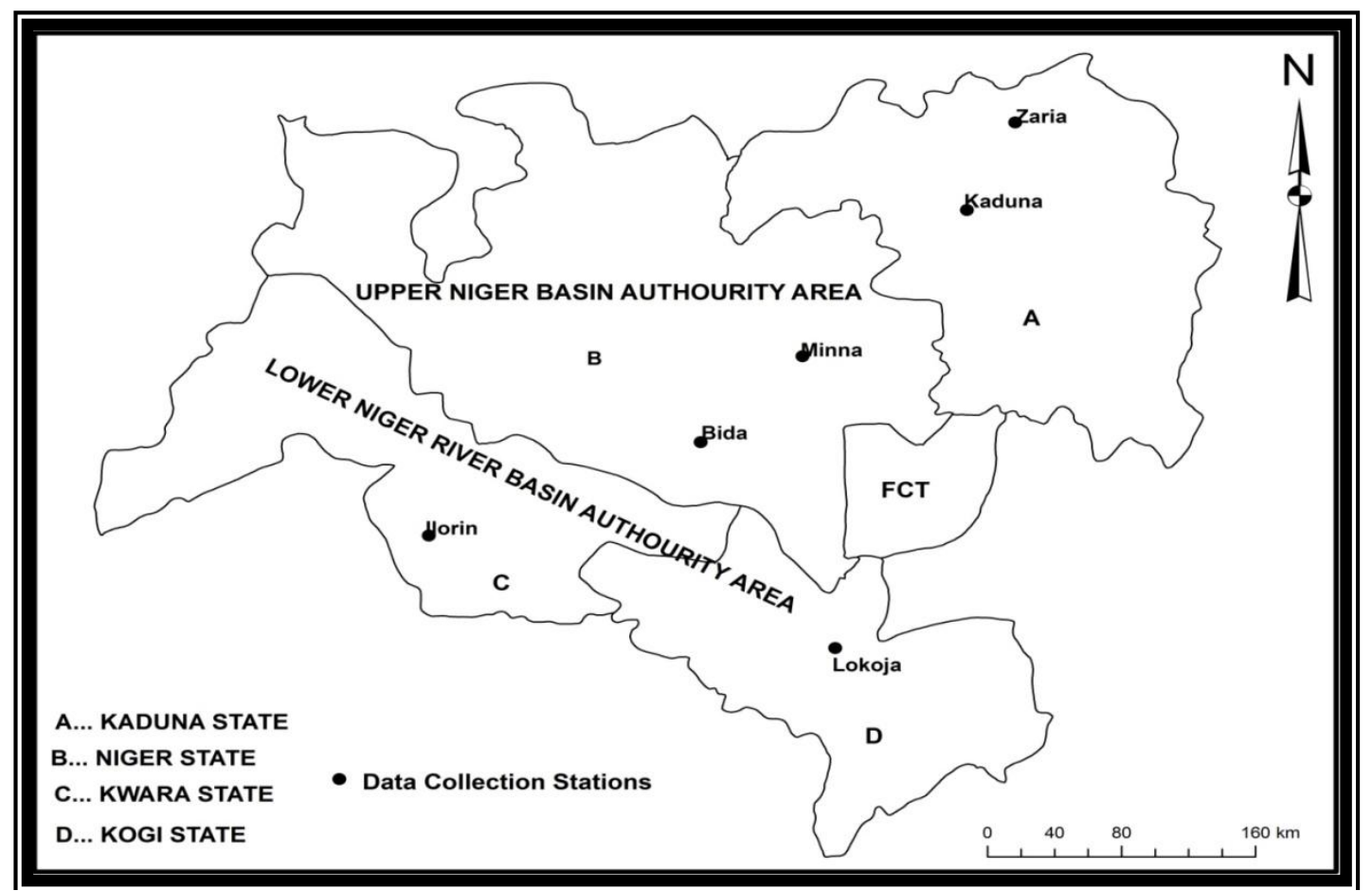

Fig. 2: Map of the upper and lower Niger River basin development authorities showing climate data collection stations.

\subsection{Data collection}

Daily rainfall data from seven stations in the study area were obtained for 70-year period, 1941-2010. Stations were selected on the basis of completeness of records. A station, Yelwa which have border with the study area was used when it is discovered that stations with complete record in the study area are few (Fig.2).

\subsection{Data analysis}

The general temporal variation of annual rainfall in U\&LNRBDA during 1941-2010 is analysed using standardized Anomaly Index. The index is the yearly average of the normalized annual rainfall departures for those stations. Its value for the year $\mathrm{j}$ is given by:

$x_{i}=\frac{r-r_{i}}{\sigma}$

Where $\mathrm{Xi}$ is the normalized departure, $\mathrm{r}$ is the year's rainfall total, ri is the mean annual rainfall and $\sigma$ is the standard deviation of rainfall totals from the mean of yearly totals for the base period. For the region, aerially integrated rainfall $\mathrm{R}$ is calculated as:

$R=I^{-I} \sum x_{i}$

Where 1 is the number of stations and summation is made over all I stations. Thus, a value of 0.5 indicates an average regional anomaly of half standard deviation from the mean.

The regional annual rainfall series was also examined for trends using spearman rank correlation coefficient. The trends were investigated for the period 1941-2010 and for two other sub-periods, 1941-1980, and 1981-2010. 


\section{Results and discussion}

\subsection{Rainfall variability in the upper and lower river basin development authority area}

During the 70 years studied (1941-2010) annual rainfall in the Upper and Lower Niger River Basin Development Area (U\&LNRBDA) fluctuated markedly around their long-term means. Figure 3 reveals distinct periods of short-term and long-term rainfall fluctuations with the period since 1970 recording long run of dry years (below long-term mean rainfall).

Figure 3 also shows that 1941-2010 period contains four district periods when rainfall pattern of the same sign was most persistent. The first is the period 1941-52 which is characterized by inter annual variability when dry years rapidly alternate with wet years. The year to year variability was relatively pronounced.

In contrast to the above, the period 1953-1969 was one when average rainfall in the U \& LNRDBDA was most persistent. The years of this period were among the wettest of the period. Most of these years experienced strong positive departures. Rainfall during this period was $6.6 \%$ above the long-term average. This is a wet period in the study area.

Another feature of Figure 3 is the extended period of below long-term average rainfall particularly since 1970 and which intensified from 1980-93. These long dry phases in the U \& LNRBDA which began in 1970 contained the severe drought of 1972/73 and those of the 1980s which have been reported in literatures for the Sahel and some parts of Africa (Janowiak, 1988; Nicholson, 1989; Hulme, 2001; Giannuni et.al., 2003; Dai et. al., 2004). The drought of $1972 / 73$ was clearly less severe compared with the drought of the 1980s. In the 1970s, rainfall over the study area was $0.9 \%$ below the long-term average while that of the $1980 \mathrm{~s}$ was $9.5 \%$ below the long-term average. A rainfall decrease of 6\% was observed in the 1970-1993 dry phase compared to the 1941-2010 mean. In the 1980s, wet year was absent and drought was the norm for the study area. The downward trend from 1920-1993 affected the whole study area, but resulted in negative impacts on food production only in the low rainfall areas.

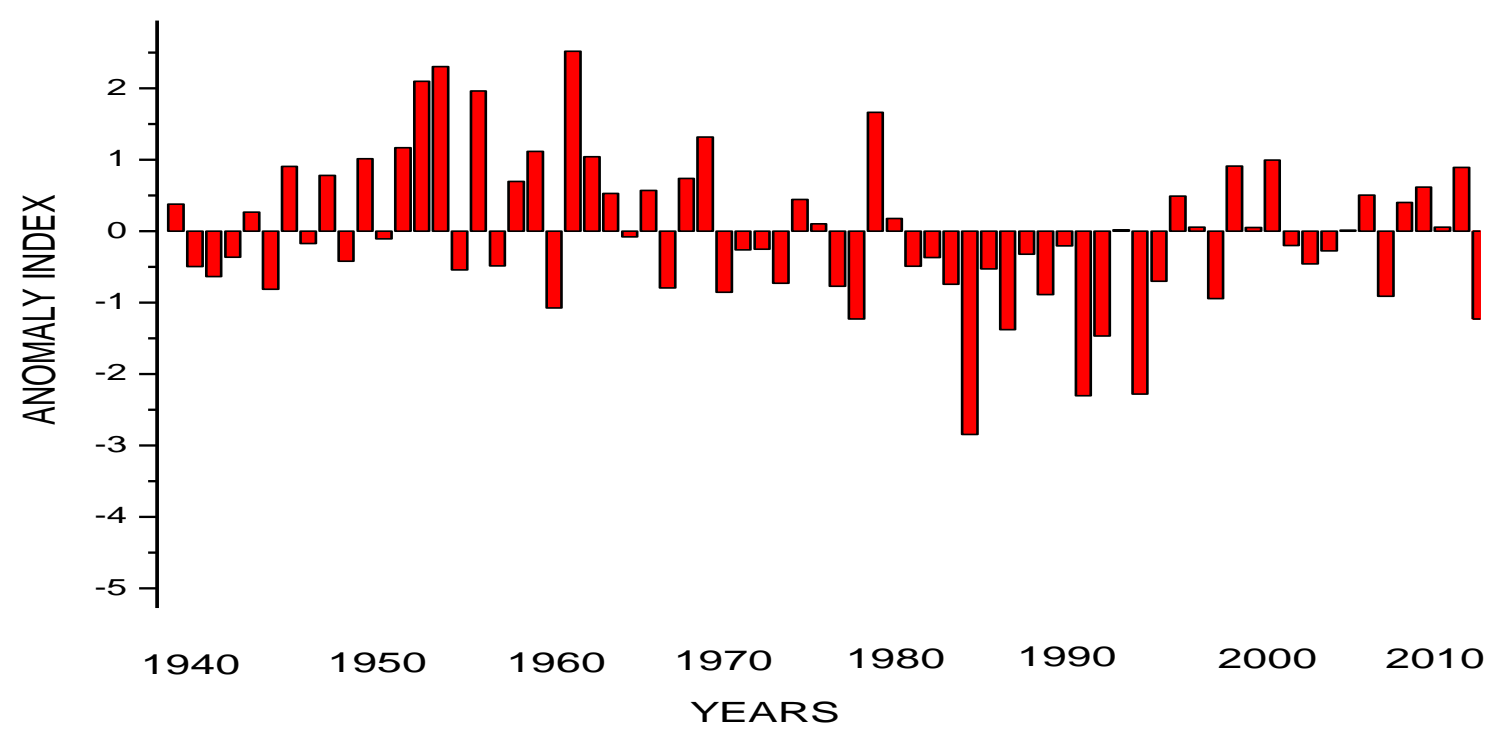

Fig. 3: Annual rainfall anomalies in the upper and lower Niger River basin development authority area.

The last phase is manifested in above average rainfall which occurred after the prolonged and persistent drought of the 1970-93. The 1994-2010 periods marked the return of rains in the study area. After a long dry period, a humid phase began in 1994 and lasting till now. The 1994-2010 was once again marked by wet climate. Some improvement in Sahel rainfall from 1990s continuing into the early 21st century was reported in literatures [20], [23].

The 70-years long rainfall record represented in Figure 3 indicates that the U\&LNRBDA experienced alternating wet and dry conditions on annual and decadal timescales. However, it was the multidecadal dry phase between 1970-1993 that was the most striking temporal characteristics of rainfall variability in the study area. Apart from this period, runs of five and more of the same anomaly are non-existent. It is also observed that it is the short-term wet and dry conditions of 1-3 years which are still the dominant mode of rainfall variability of the study area. Analysis of rainfall in many parts of Africa shows a predominance of short-term variability on time scales of 2-3 years [8-10]. It is not only the annual rainfall that is highly variable in the study area but also inter decadal means. 
Table 1 show that rainfall variability at decadal time-scale ranges from $-9.5-7.8 \%$. During the period studied, 1951-60 decade is the wettest being $7.8 \%$ above the long-term mean and 1981-90 which is $9.5 \%$ below the long-term mean was the driest. From the table, it is observed that the drought of the 1970s which captured the attention of the whole world, was clearly less severe compared with the drought of the 1980s in the study area. The table also shows that rainfall in the study area started recovering from the 1990s and reaches the long-term mean during the 2001-2010 decade.

Table 1: Deviation of decadal rainfall means from the long-term means in the upper and lower Niger River basin development authority areas.

\begin{tabular}{ccc}
\hline Decade & \% Deviation from the long-term mean \\
$1941-50$ & 0.0 \\
$1951-60$ & +7.8 \\
$1961-70$ & +3.4 \\
$1971-80$ & -0.9 \\
$1981-90$ & -9.5 \\
$1991-2000$ & +1.3 \\
$2001-2010$ & 0.0 \\
\hline
\end{tabular}

\subsection{Trends in annual rainfall in the upper and lower Niger River basin development authority areas.}

The annual rainfall events for the period 1941-2010 and sub-period, 1981-2010 in the study area were examined for trends. They were subjected to testing for dominant trends using the Spearman's correlation co-efficient. The results show clearly that annual rainfall records in the period 1994-2000 were found to demonstrate no pronounced temporal decreasing or increasing trends. The lack of significant trend in annual rainfall in the study area during 1941-2010 may be due to the fact that the rainfall series is characterized by large temporal variability. IPCC (2007) reported a statistically insignificant linear trend for the global average rainfall from GHCN during 1901-2005. Not even the trend estimates for 1951-2005 that is significant.

However, a positive significant trend (0.4020 at 99\% significance level) was observed for the subperiod 1981-2010. This indicates that rainfall increased during this period in the study area. Starting in 1994 the study area has recorded a series of good years (frequently accompanied by floods). The run of good average rainfall years since 1994 may be announcing the end of the region's drying trend. However, the reality is that rainfall will continue fluctuating and that good and bad years will continue occurring.

\section{Conclusion}

The study has been able to establish that the trend annual series during the period 1941-2010 in the Upper and Lower Niger River Basin Development Authority Areas is statistically significant but not for the period 1981-2010. An increasing trend is observed during 1981-2010 subperiod. Despite the fact that rainfall has come back to near normal since the 1990s, the study area remains an environmentally sensitive region and climate is likely to exacerbate the vulnerability of its ecological and socio economic systems. In that case even through the studies of annual rainfall variability are of prime importance in investigations of impact of rainfall change on water resources and agriculture in the study area, analyses of the rainfall parameter is essential.

\section{Acknowledgements}

The authors appreciated TETFUND whose financial support make this study possible. The authors also acknowledge the Nigeria Meteorological Agency for the temperature data.

\section{References}

[1] Intergovernmental Panel on Climate Change (IPCC), 2007. Climate Change 2007: Impacts Adaptation and Vulnerability. Contribution of working group II to the Fourth Assessment Report of the Intergovernmental Panel on Climate Change. Cambridge University Press, Cambridge.

[2] Intergovernmental Panel on Climate Change (IPCC), 1996. Climate Change 1996. The Science of Climate Change: Contribution of working group 1 to the Second Assessment Report of the Intergovernmental Panel on Climate Change. Cambridge University Press, Cambridge.

[3] J. M. Melillo, 1999. Warm, Warm on the Range. Science 283, 183-184. 
[4] D. E Parker, 2000. Temperatures High and Low, Science, 287, 1216-1217.

[5] W.Karlen, 2005. Recent Global Warming. An Artifact of a Too-short Temperature Records, Ambio 14(33), 263-264

[6] E, Kjellstrom, 2004. Recent and Future Signatures of Climate Change in Europe. Ambio, 33(4-5).

[7] A. Giannini, R, Saravanan and P, Chang, 2003. Oceanic Forcing of Sahel Rainfall on International to Interdecendal Timescales. Science 302, 1027-1030.

[8] J. S. Oguntoyinbo, 1982. Climate Variability and Food Crop Production in West Africa. GeoJournal 5(2), 139-150.

[9] O, Ojo, 1987. The Climate Drama. Inaugural Lecture Series, University of Lagos, Lagos. University of Lagos press, 1-36 pp.

[10] O. J. Olaniran, and G. M Summer, 1990. Long-term Variation of Annual and Growing Season Rainfalls in Nigeria. Theor and Appl Clim. 41, 41-53.

[11] S. E. Nicholson, 1989. Long-term Changes in African Rainfall, Weather, 44(4), 46-56.

[12] S. E. Nicholson, and D. Entekhabi, 1986. The Quasi-periodic Behavior of Rainfall Variability in Africa and its Relationship to the Southern Oscillation. Arch. Meteorol. Geophys. Bioklimatol Ser. A. 34,311-345.

[13] S. E. Nicholson, 2001: Climate and Environmental Change in Africa during the Last Two Centuries. Clim. Res. 17(2), 123-144.

[14] J. S. Babatolu, 1998. Climate Change and its Implication for Water supply in the Niger River Basin Development Authority Area, An unpublished Ph.D. Thesis submitted to the Department of Geography, University of Ilorin, and Ilorin.

[15] S.Barriers, H.Bertinelli, E Strobi, 2006. Climate Change and Rural-urban Migration: The Case of Sub-Saharan Africa. J. Urban Econ. 60(3) 357-371.

[16] P. V. Desanker and C. O. Justice, 2001. Africa and Global Climate Change: Critical Issues and Suggestions for Further Research and Integrated Assessment Modeling. Clim Res. 17(2), 93-103.

[17] A. Chappel and C. T Agneir, 2004 Modeling Climate Change in West Africa Sahel Rainfall (1931090) as an Artifact of Changing Station Locations . Int. J. Climatol. 24(5), 547-554.

[18] A. Dai., P. J., Lamb, , K. E. Trenberth, M. Hulme, P. D, Jones, P. Xie, 2004. The Recent Sahel Drought is Real. Int. J. Climatol, 24; 13231331.

[19] M Boko, I Niang, A Nyong, , C Vogel,. A Cutheko, , M.Medany, B. Osman-Elasha R Tobo, P. Yonda, 2007 Africa In: Parry in Canzianio, Palutikof J, Vander Lenden, P, Harison C. editors. Climate Change 2007: Impacts, Adaptation and Vulnerability. Working Group II Contribution to the Forth Assessment Report of the Intergovernmental Panel on Climate Change. Cambridge (UK) Cambridge.

[20] Y.,Malhi, and J. Wright, 2004. Spatial Patterns and Recent Trends in the Climate of Tropical Rainfall Regions. Philos. Trans. R. S. B, 359(1443)-311-329.

[21] C. J., Schreck, F.H.M, Sernazzi, 2004. Variability of the Recent Climate of Eastern Africa. Int. J. Climate. 24(6):681-701.

[22] M. G. New, M. Hulme, and P.D. Jones, 2000. Representing 20th Century Space-time Climate Variability. Part II: Development of 1901-1996 Monthly Terrestrial Climate Fields. Journal of Climate 3(13), 2217-2238.

[23] N, Brooks, 2004. Drought in the African Sahel: Long-term Perspective and Future Prospect.Tyndall Centre Working paper, No. 61, October 2004. 